\title{
Influence of Seawater Flow Velocity on the Morphological Characteristics of Calcareous Deposits Formed by Cathodic Protection
}

\author{
Chengjie $\mathrm{Li}^{1, \mathrm{a}}$, Xin $\mathrm{Cui}^{1}$ \\ ${ }^{1}$ Weifang University of Science and Technology, \\ Shouguang, 262700, China \\ ${ }^{\mathrm{a}}$ Licj@foxmail.com
}

\author{
Min $\mathrm{Du}^{2}$ \\ ${ }^{2}$ The Key Laboratory of Marine Chemistry Theory and \\ Technology, Ministry of Education, \\ College of Chemistry and Chemical Engineering, Ocean \\ University of China, \\ Qingdao 266100, China
}

\begin{abstract}
The influence of seawater flow velocity on calcareous deposits formed under galvanostatic polarization mode was studied. The protection potentials of electrodes shifted positively with increasing flow velocities which were monitored versus time at various flow velocities. The whole curves of potential decay appeared two inflection points, corresponding to the different processes of crystal sedimentation. Observation by scanning electron microscope and $\mathrm{X}$-ray diffraction analyses demonstrated that the ratio of magnesium in the deposits increased with flow velocities, and the main kind of crystal was brucite when the velocity was higher than $10 \mathrm{~cm} / \mathrm{s}$.
\end{abstract}

Keywords-seawater; calcareous deposits; flow velocity; galvanostatic; cathodic protection.

\section{INTRODUCTION}

Calcareous deposits, formed on the metallic surface in seawater under cathodic protection (CP), act as a physical barrier which can hinder the diffusion of oxygen. Therefore, the presence of this chemical layer can decrease the cathodic current density, or the sacrificial anode consumption, leading to high efficient and economical control of corrosion using $\mathrm{CP}$ in seawater[1,2]. The formation mechanism of calcareous deposits has been studied extensively[3-5]. And there are several factors that can influence the deposits formation in seawater[6-8]. Flow velocity is one of the most important factors because it can influence the ions diffusion rates and the thickness of diffusion layers on the metallic surface.

In this study, specific attention has been focused upon the influence of the flow velocity of seawater on the calcareous deposits by galvanostatic polarization mode. The protection potential was monitored versus time. Scanning electron microscope (SEM) coupled with X-ray diffraction (XRD) was used here to investigate the morphology of deposits, and energy dispersive X-ray spectroscopy ( EDX) was also used to analyse the composition of calcareous deposits.

\section{EXPERIMENTAL}

All experiments were performed in natural seawater $(\mathrm{pH}$ 8.1) with the salinity of 32 from Maidao, a coastal scientific station in Qingdao, China. The seawater was filtered through $0.7 \mu \mathrm{m}$ pore-size glass fiber filters to clear the marine growth. The working electrode was carbon steel
Q235, with approximate composition (in weight \%) of: $99.32 \% \mathrm{Fe}, 0.18 \% \mathrm{C}, 0.02 \% \mathrm{Si}, 0.45 \% \mathrm{Mn}, 0.02 \% \mathrm{~S}$, and $0.01 \%$ P. The plate metal samples were polished with 600 , 1000,2000 -grit paper in sequence, followed by ultrasonical cleaning and air-dried treatment prior to insertion in the test cell (Fig.1). The potentials were measured versus the $\mathrm{Ag} / \mathrm{AgCl} /$ seawater electrode. A large Mixed Metal Oxide (MMO) grid was used as the counter electrode.

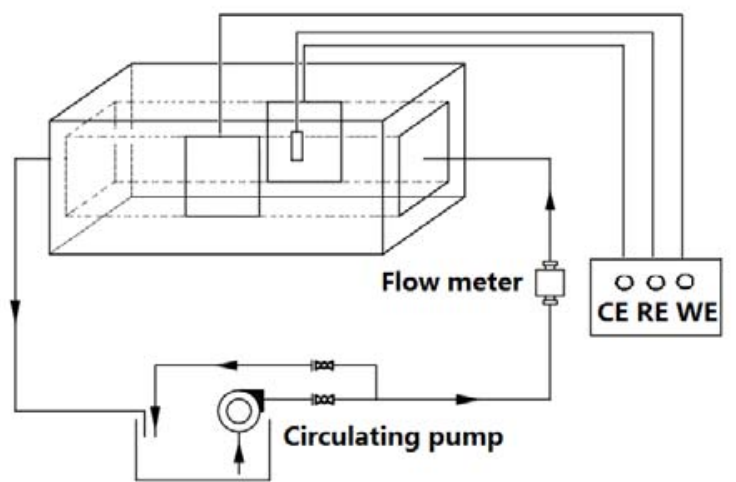

Fig.1. Schematic illustration of the electrochemical cell for controlling seawater flow velocity

The flowing seawater was supplied by a water pump, of which velocity was controlled to $5,10,20,30$ and $40 \mathrm{~cm} / \mathrm{s}$ respectively by a flow meter. And the temperature of seawater was controlled to $25 \pm 1^{\circ} \mathrm{C}$, the concentration of dissolved oxygen was under the natural status at the temperature. A current density of $300 \mathrm{~mA} / \mathrm{m} 2$ was used to maintain the same total charges in individual polarization experiment by galvanostatic polarization method. All of the experiments were performed for $168 \mathrm{~h}$ to guarantee the electrodes could reach the relative stable protection state.

SEM observations by JEOL JSM-6700F were performed to characterize the deposits, whose chemical compositions were analysed using EDX. XRD of D8 ADVANCE was also involved to analyse crystalline form using small-angle diffraction due to the thin deposits. The electrodes covered by deposits for the surface investigation were rinsed thoroughly with distilled water to reduce the interference from $\mathrm{NaCl}$ and other salts. 


\section{RESULTS AND DISCUSSION}

\section{A. Potential decay at various flow velocities}

The potentials of electrodes were monitored versus time at various flow velocities. As can be seen from Fig. 2, the potentials decreased to more negative values with time in all galvanostaitc experiments. Generally, the potential curves of all the flow velocities went through three stages containing two inflection points. The first inflection point appeared in the initial $15 \mathrm{~h}$ of polarization. During this period, the potential curves trended as almost the same which shifted negatively with polarization time, and then reached a plateau. The plateau came to an end after a certain period, the length of which was influenced obviously by the flow velocity. The lager the flow velocity was, the longer the plateau. And the plateau did not come to an end in the experimental period at the flow velocity of $40 \mathrm{~cm} / \mathrm{s}$. After the plateau appeared the second inflection point. Then the protection potentials shifted negatively again.

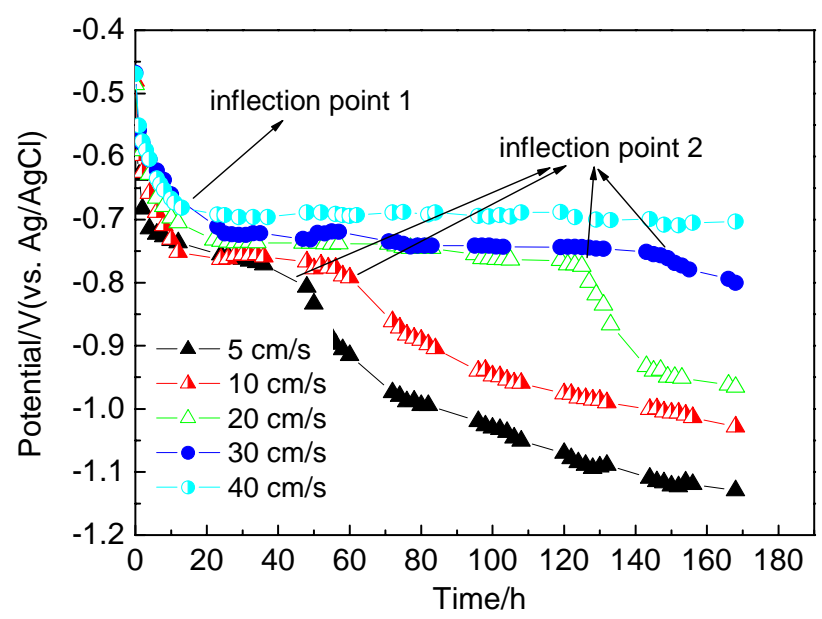

Fig.2. Potential decay curves vs. time at various flow velocities by galvanostaitc polarization

It was assumed that the two inflection points were due to the different crystal deposition stages. Magnesium hydroxide with less protective qualities[9] was the dominant film before the second inflection point. After that the calcium carbonate film began to precipitate and played a major protecting role especially at low flow velocities, which was verified by the morphological studies part. After $168 \mathrm{~h}$ polarization, the potential shifted positively with flow velocity, and the potential could reach exactly the protection potential of $-0.78 \mathrm{~V}(\mathrm{Ag} / \mathrm{AgCl})$ at the flow velocity of 30 $\mathrm{cm} / \mathrm{s}$, while it did not reach the protection status at $40 \mathrm{~cm} / \mathrm{s}$ even after $168 \mathrm{~h}$ polarization.

\section{B. Morphological characters}

The calcareous deposits were investigated by SEM at various flow velocities after $168 \mathrm{~h}$ galvanostatic polarization (Fig.3) and significant changes on the deposits morphology was observed. At the flow velocity of $5 \mathrm{~cm} / \mathrm{s}$, the deposits were mainly orthorhombic crystals, which were considered as aragonite with typical cauliflower morphology[]10]. The crystal forms of deposits at this flow velocity were proved to be aragonite of calcium carbonate by the XRD analysis (Fig.4).
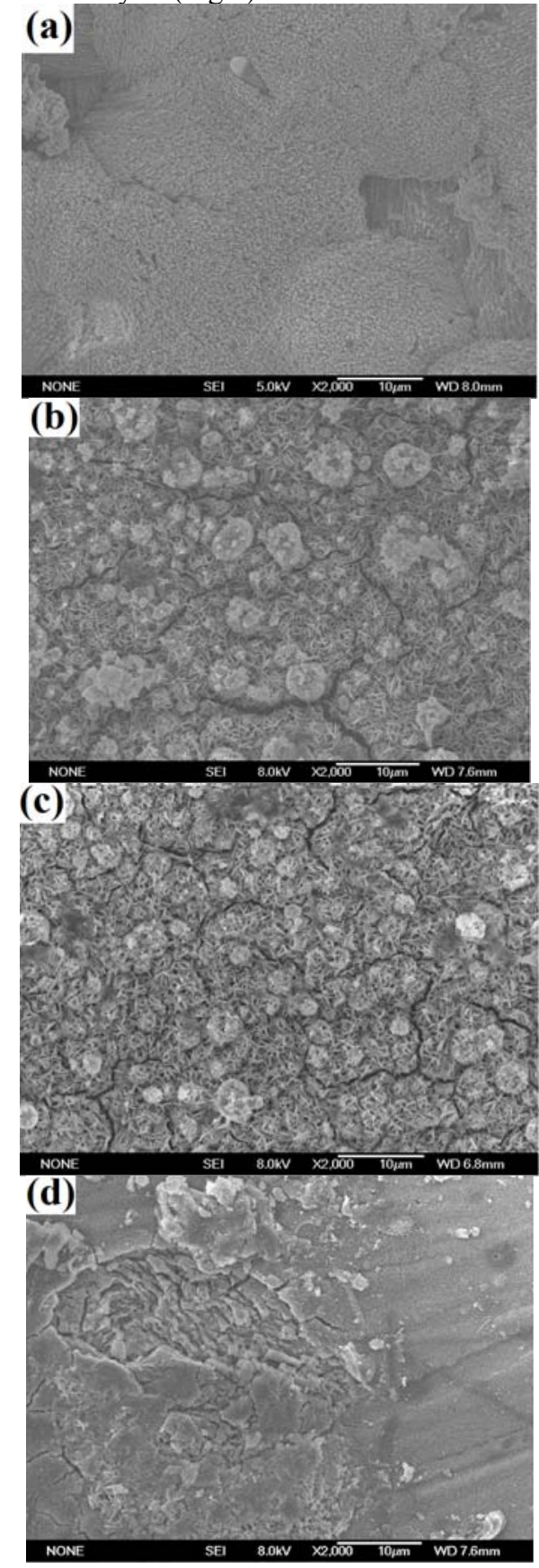


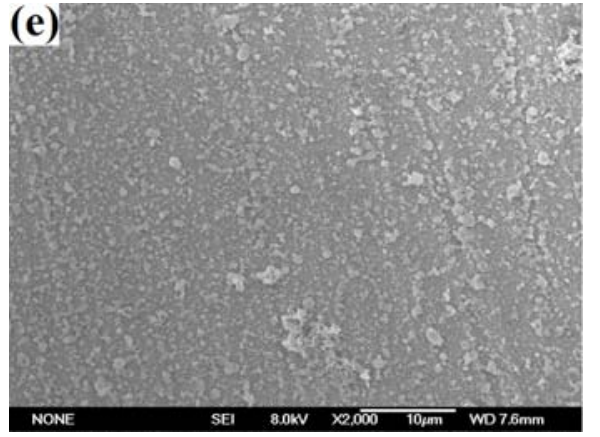

Fig.3. SEM observations of the electrodes surfaces at various flow velocities after galvanostaitc polarization for $168 \mathrm{~h}$ :

(a) $5 \mathrm{~cm} / \mathrm{s}$; (b) $10 \mathrm{~cm} / \mathrm{s}$; (c) $20 \mathrm{~cm} / \mathrm{s}$; (d) $30 \mathrm{~cm} / \mathrm{s}$; (e) $40 \mathrm{~cm} / \mathrm{s}$

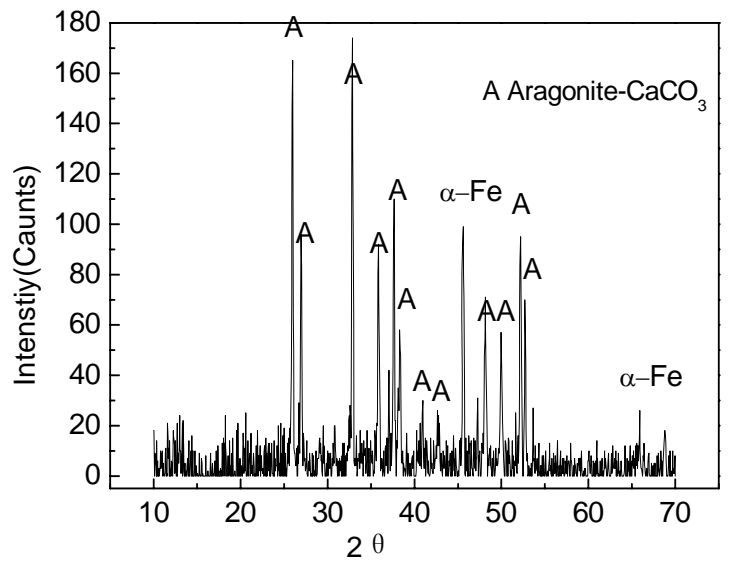

Fig.4.XRD analysis of the deposits formed at $5 \mathrm{~cm} / \mathrm{s}$ on a steel substrate

While when the flow velocity was higher than $10 \mathrm{~cm} / \mathrm{s}$, there no typical cauliflower deposits with large crystal size were found in the SEM photographs of 2000 magnification. At the flow velocity of 10 and $20 \mathrm{~cm} / \mathrm{s}$, only a small amount of granular deposits was found on the suface of the electrodes, which was considered as the initial stage of the calcium carbonate sedimentary characteristics. This was verified by the EDX results. Futher more, cauliflower deposits with large crystal size were observed in a large field of view in the low magnification SEM image of $500 \times$ (Fig.5). And the results of EDX for the ctystal partical of zone (a) and the base of zone (b) verified that the composition of partical was mainly $\mathrm{Ca}$, which was aragonite of calcium carbonate. The the composition of base was mainly $\mathrm{Mg}$, which was brucite of magnesium hydroxide. This could also prove that magnesium hydroxide deposited firstly, and then calcium carbonate formed on the flim of magnesium hydroxide, which corresponded to the potential decay curves in Fig.2.
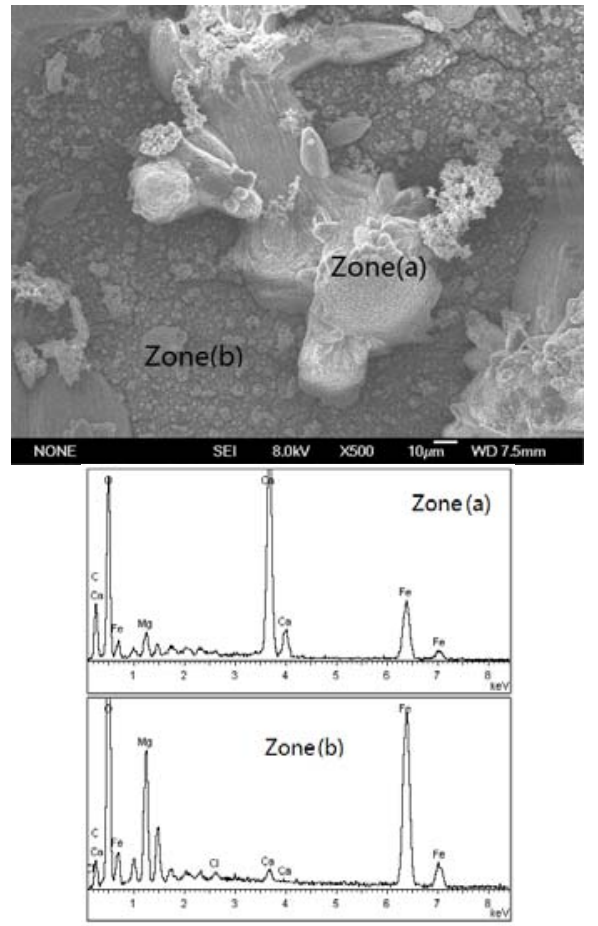

Fig.5. Low magnification SEM image of the electrode surface at a flow rate of $10 \mathrm{~cm} / \mathrm{s}$ and the EDX results

When the flow velocity was higher than $30 \mathrm{~cm} / \mathrm{s}$, there even no crystal particles was observed in Fig.3(d) and (e), and the grinding scratches on the electrode surface were faintly visible. However, magnesium hydroxide with acicular structure could be observed in the much higher magnification SEM image of $10000 \times$ (Fig.6), indicating the deposits were mainly magnesium hydroxide at higher flow velocities.

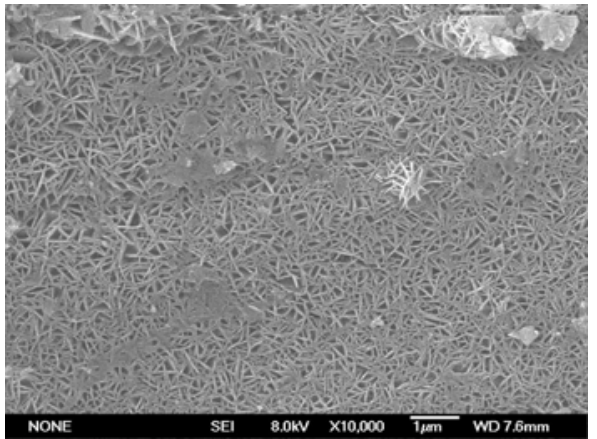

Fig.6. High magnification SEM of the electrode surface at flow a rate of 30 $\mathrm{cm} / \mathrm{s}$

In order to analyse the proportion of calcium and magnesium in the deposits formed at various flow velocities, EDX was performed (Table 1). 
TABLE 1. THE ATOMIC RATIO OF CA/MG BY EDX ANALYSES AT VARIOUS FLOW RATES

\begin{tabular}{cccc}
\hline$v(\mathrm{~cm} / \mathrm{s})$ & $\mathrm{Ca}(\mathrm{mol} \%)$ & $\mathrm{Mg}(\mathrm{mol} \%)$ & $\mathrm{Ca} / \mathrm{Mg}$ \\
\hline 5 & 14.31 & 0.2 & 71.55 \\
10 & 11.20 & 1.66 & 6.75 \\
20 & 0.14 & 9.52 & 0.015 \\
30 & 0.062 & 7.74 & 0.0080 \\
40 & 0.019 & 3.07 & 0.0061 \\
\hline
\end{tabular}

The ratio of $\mathrm{Ca} / \mathrm{Mg}$ in deposits decreased sharply with increasing flow velocities, which meaned calcium carbonate decreased at higher flow velocities. This was because of the relatively large crystal grain size, calcium carbonate sustained a greater impact by flowing seawater, leading to it hard to deposit on the electrode suface at a higher flow velocity. However, magnesium hydroxide particle size was relatively smaller, and sustained a smaller impact by the flowing seawater. Therefore, magnesium hydroxide was relatively easily to deposit on the electrode surface in flowing phase.

\section{CONCLUSIONS}

Galvanostatic polarization experiments were carried out to study the influence of the flow velocities on the morphological characteristics of calcareous deposits.

The polarization potential of the electrode appeared two inflection points, corresponding to the different processes of crystal sedimentation. Magnesium hydroxide deposited firstly, and then calcium carbonate formed on the flim of magnesium hydroxide. The final potential shifted positively with increasing flow velocities. Morphological results revealed that the ratio of $\mathrm{Ca} / \mathrm{Mg}$ in deposits decreased sharply with increasing flow velocities, illustrating a decreasing content of calcium carbonate in deposits. The main crystal form of deposits was aragonite of calcium carbonate at $5 \mathrm{~cm} / \mathrm{s}$, while it was mainly brucite ofmagnesium hydroxide at higher flow velocities.

\section{REFERENCES}

[1] Rossi, S., Bonora, P.L., Pasinetti, R., Benedetti, L., Draghetti, M. \& Sacco, E., Laboratory and field characterization of a new sacrificial anode for cathodic protection of offshore structures. Corrosion, 54(12), pp. 1018-1025, 1998

[2] Barchiche, C., Deslouis, C., Gil, O., Refait, P. \& Tribollet, B., Characterisation of calcareous deposits by electrochemical methods: role of sulphates, calcium concentration and temperature. Electrochimica Acta, 49 (17-18), pp. 2833-2839, 2004.

[3] Luo, J.S., Lee, R.U., Chen, T.Y., Harrt, W.H. \& Smith, S.W., Formation of calcareous deposits under different modes of cathodic polarization. Corrosion, 47(3), pp. 189-196, 1991.

[4] Mantel, K.E., Hartt, W.H. \& Chen, T.Y., Substrate, surface finish, and flow rate influences on calcareous deposit structure. Corrosion, 48, pp. 489-500, 1992.

[5] Deslouis, C., Festy, D., Gil, O., Rius, G., Touzain, S. \& Tribollet, B., Characterization of calcareous deposits in artificial seawater by impedance techniques: 1. Deposit of $\mathrm{CaCO}_{3}$ without $\mathrm{Mg}(\mathrm{OH})$. Electrochimica Acta, 43(12-13), pp. 1891-1901, 1998.

[6] Beaunier, L., Gabrielli, C., Poindessous, G., Maurin, G. \& Rosse, R., Investigation of electrochemical calcareous scaling nuclei counting and morphology. Journal of Electroanalytical Chemistry, 501, pp. 41-53, 2001.

[7] Barchiche, C., Deslouis, C., Gil, O., Joiret, S., Refait, P. \& Tribollet, B., Role of sulphate ions on the formation of calcareous deposits on steel in artificial seawater: the formation of Green Rust compounds during cathodic protection. Electrochimica Acta, 54(13), pp. 3580-3588, 2009.

[8] Benedetti, A., Magagnin, L., Passaretti, F., Chelossi, E., Faimali, M. \& Montesperelli, G.., Cathodic protection of carbon steel in natural seawater: Effect of sunlight radiation. Electrochimica Acta, 54(26), pp. 6472-6478, 2009.

[9] Neville, A., \& Morizot, A.P., Calcareous scales formed by cathodic protection--an assessment of characteristics and kinetics. Journal of Crystal Growth, 243, pp. 490-502, 2002.

[10] Barchiche, C., Deslouis, C., Festy, D., Gil, O., Refait, P., Touzain, S. \& Tribollet, B., Characterization of calcareous deposits in artificial seawater by impedance techniques: 3--Deposit of $\mathrm{CaCO}_{3}$ in the presence of Mg (II). Electrochimica Acta, 48, pp. 1645-1654, 2003. 